\title{
BRIEF
}

\section{Ensuring Student Practice Readiness: Mapping Course Assessments to Canadian Pharmacy Educational Outcomes}

\author{
Aleksandra Bjelajac Mejia, PharmD, Lachmi Singh, PhD, Jacqueline Flank, MSc, Gajan Sivakumaran, MA \\ University of Toronto, Leslie Dan Faculty of Pharmacy, Toronto, Ontario
}

Corresponding Author: Aleksandra Bjelajac Mejia, University of Toronto, Leslie Dan Faculty of Pharmacy, 144 College St, Toronto, ON, M5S 3M2. Tel: 416-978-2889. Email: sandra.bjelajac@utoronto.ca

Submitted May 10, 2021; accepted August 26, 2021; ePublished September 2021

Objective. The entry-to-practice PharmD program is designed to meet the Association of Faculties of Pharmacy of
Canada (AFPC) Educational Outcomes (EOs). We set out to evaluate how assessment strategies in a 'capstone' course
align with AFPC EOs, their respective key and enabling competencies, and whether there are a sufficient number of
assessments for students to demonstrate achievement of competencies prior to embarking on advanced pharmacy practice
experiences.

Methods. Each assessment's objectives, content and methods were mapped to key and enabling competencies of each role. The number of enabling competencies mapped represented the extent to which the associated key competency and broader role was assessed. De-identified student performance data were analyzed to identify achievement of competencies despite failed assessments.

Results. Of the seven role descriptions, Care Provider, Communicator, and Collaborator were the most comprehensively assessed. Leader-Manager and Health Advocate roles were assessed to a limited extent. The Scholar role was not covered to a great depth across assessments. The Professional role was not represented in most assessments except for the final exam. Students with failed assessments generally had ample opportunity to demonstrate competencies through other assessments.

Conclusion. Mapping assessments to AFPC EOs is an essential step to demonstrate direct evidence of achievement of the intended learning outcomes. Our map revealed that there was sufficient overlap in the assessment of most AFPC EOs with a few exceptions. It is important to create multiple opportunities within a course for students to demonstrate achievement of competencies to ensure practice readiness.

Keywords: assessments, competencies, APPE, mapping, alignment

\section{INTRODUCTION}

In Canada, the Canadian Council for Accreditation of Pharmacy Programs (CCAPP) sets standards for pharmacy programs for quality assurance and program enhancement. ${ }^{1}$ These standards include that a program must be "based on an organized educational framework that facilitates development of graduates with competencies to meet the entry-level scope of practice." ${ }^{1}$ The educational framework must be based on Association of Faculties of Pharmacy of Canada (AFPC) Educational Outcomes (EOs) ${ }^{2}$ and National Association of Pharmacy Regulatory Authorities (NAPRA) Standards. ${ }^{3}$ As part of CCAPP standard one, criterion 1.2, pharmacy programs must produce evidence that "students demonstrate practice-readiness that enables them to provide patient care as a collaborative member of a care team before culminating direct patient care required practice experiences." ${ }^{1}$ In 2017, AFPC EOs were updated drawing on several international pharmacy education frameworks. ${ }^{4-6}$ In preparation for accreditation and in recognition of the updated EOs, we set out to map and analyze course assessments and students' performance in a required course.

Over the past few years, under the auspices of the Education Office, course coordinators updated course outlines to align with these new AFPC EOs. These outcomes are comprised of seven major roles: Care Provider, Communicator, Collaborator, Leader-Manager, Health Advocate, Scholar, and Professional. Students are expected to demonstrate achievement of these EOs to graduate. The EOs are further subdivided into key competencies that represent measurable behaviours, and within each key competency there are enabling competencies that denote specific skills and behaviours necessary for practice readiness. The 2017 AFPC EOs with descriptions of roles and key competencies are provided in Table 1. While enabling competencies are not shown in this table, they are available in the 2017 AFPC EO Report. ${ }^{2}$ Although, mapping individual course learning outcomes in relation to these new EOs is important, we set out to go beyond content mapping to determine if course assessments provide students with adequate opportunities to demonstrate achievement of practice readiness for Advanced Pharmacy Practice Experiences (APPEs). ${ }^{7}$ 
We chose to complete this assessment mapping in a third year required course, Preparation for APPE, which all students must pass prior to commencing APPE rotations. A growing body of research has shown the importance of a preparatory experiential rotation course to optimize pharmacy student learning through successful demonstration of practice readiness. ${ }^{8-10}$ This half-credit course was implemented in 2014, as part of the new PharmD program curriculum, to prepare students for culminating fourth year experiential rotations through consolidation of knowledge, skills and attitudes learned throughout the curriculum. The positionality of this course made it particularly apt to examine whether course assessments were purposeful in assessing EOs and associated competencies. ${ }^{11}$ We anticipated gaining a better understanding of whether course assessments offered students opportunity to demonstrate practice readiness while informing course quality improvements. ${ }^{12}$

This study draws on the theoretical framework of assessment blueprinting which is defined as "the process of linking tests to learning goals." 12 While the course coordinator already blueprinted assessments to ensure that they effectively tested course content, it was determined that the process should extend to blueprinting assessments to explore if they sufficiently mapped to intended EOs. There are two key advantages of mapping course assessments to competencies. First, it helps course instructors articulate course expectations and helps students understand the focus of learning experiences. Second, it enables the instructor to be strategic in their teaching activities, assessment planning, and ability to provide direct evidence that course assessments provide an opportunity for students to demonstrate competencies while ensuring constructive alignment throughout the course. ${ }^{13}$ These processes ultimately create "significant learning experiences" whereby students have varied opportunities to demonstrate their practice readiness and achievement of EOs. ${ }^{14}$

\section{OBJECTIVE}

Our study set out to address two main research questions. First, do current course assessments align with intended AFPC EOs as outlined in the course learning objectives? Second, are there a sufficient number and variety of assessments for students to demonstrate achievement of AFPC EOs and associated key and enabling competencies? By addressing these questions, we add to the limited but evolving body of literature in health professions education on purposeful assessment strategies in competency-based education. ${ }^{15-17}$

\section{METHODS}

In the Preparation for APPE course (2018-2019), data from the six assessments (e.g., format, weight, type) were provided by the course coordinator. An overview of the assessments and their main objectives is highlighted in Table 2 . To determine if there is sufficient overlap in assessments for students to demonstrate practice readiness for APPEs, deidentified student performance data, on all six assessments, was collected from the learning management system and used to identify failed assessments. A failed mark was defined as below $60 \%$ as per the Faculty Grading Policy. Ethics approval was obtained from the University of Toronto Health Sciences Research Ethics Board.

Assessment mapping of our six assessments was performed by two research team members using a systematic process considering the format (eg, written, video, exam), assignment/exam blueprint, and assessment rubric. For each assessment, these components were mapped to defined enabling competencies. ${ }^{2}$ Each researcher made a dichotomous decision whether the component did or did not fit the description of the enabling competency. Any discrepancies were resolved by consensus. The number of enabling competencies mapped per key competency indicated the extent to which key competencies in each role were assessed in that assessment.

\section{RESULTS}

The assessment map is shown in Table 3. Out of all seven roles, Care Provider, Communicator, and Collaborator were most comprehensively assessed based on the number of enabling competencies covered in at least four of the six assessments. Leader-Manager and Health Advocate roles were assessed to a limited extent. While the Scholar role was covered in most assessments, typically less than half of enabling competencies were assessed. Finally, the Professional role was not represented in most assessments, although the final exam assessed all key and enabling competencies of this role description.

When student performance trends across assessments were examined ( $\mathrm{n}=233$ students), we identified that 38 students failed at least one assessment, and four of these students failed two assessments. For students who failed only one assessment $(\mathrm{n}=34)$, our assessment map showed that there was sufficient overlap in competency coverage with other assessments so that students were still able to demonstrate achievement of EOs. The only exception to this is if a student 
failed the final exam, which was the only assessment that comprehensively assessed the Professional role. However, in our analysis of students that failed only one assessment, they all passed the final exam.

For students who failed two assessments $(n=4)$, our failure patterns analysis in Table 3 illustrates how all but one student were still able to demonstrate practice readiness in all competencies across the other four passed assessments. For example, even though students A and D failed the patient case presentation and documentation assessments, Table 3 shows that there was opportunity in the care plan assessment and final exam to demonstrate practice readiness, due to overlap in competencies that were not achieved in the failed assessments. An exception to this is student $\mathrm{C}$ who failed the final exam, which we noted earlier as being the only assessment to cover the Professional role, and therefore they did not have the opportunity to demonstrate competency in the other course assessments. No students failed more than two assessments, and all students passed the course.

\section{DISCUSSION}

Our mapping process revealed there are multiple opportunities in the course for students to demonstrate achievement of most AFPC EOs, including key and enabling competencies within each role statement. Within competency-based health professions education, Norcini and colleagues have discussed the value of a purposeful system of assessments, and it is important to contextualize our map findings within this framework. ${ }^{15}$ Care Provider, Collaborator, and Communicator are roles that were assessed to the greatest extent across most assessments. This purposeful overlap depicted in our map concords with the importance of ensuring that students have multiple opportunities to demonstrate practice readiness. ${ }^{17}$ These assessments were also designed to simulate experiences that students will face in APPE rotations, which is consistent with recommendations by Holmboe and colleagues that emphasize careful planning of diverse assessments which consider the clinical setting. ${ }^{16}$

Our map revealed an assessment gap regarding the Leader-Manager and Health Advocate roles. It was challenging mapping these roles as they were not explicitly assessed. This aligns with a recent review by Dennis et al., which highlights how outcomes related to advocacy and leadership are scarce in publications about APPE rotations in the United States. ${ }^{18}$ Previous research also highlights the difficulty in assessing the Health Advocate role and related competencies in Canadian medical education. ${ }^{19}$ Therefore, it is important to carefully consider various assessment approaches and identify which might be most appropriate for fully assessing these roles and their related competencies ${ }^{20,21}$ Having an intentional approach as proposed by Janke and colleagues, could better integrate the underassessed Leader-Manager and Health Advocate roles, thereby addressing assessment gaps. ${ }^{22}$

Our map also showed the importance of considering depth versus breadth of competency coverage across assessments, defined as number of enabling competencies assessed within an assessment, and number of enabling competencies assessed across all six assessments, respectively. The Professional role was only assessed in the final exam (depth) and the Scholar role was assessed across all assessments (breadth). Our finding that the final exam was the only assessment which assessed the Professional role reveals a gap in our assessment approach. Our student performance analysis shows one student failed the final exam. This student did not have another opportunity to achieve the Professional role competencies. Ideally, there should be opportunity across multiple assessments to demonstrate proficiency while also having focused assessments where certain outcomes are assessed to a greater extent to ensure balanced breadth and depth, respectively. Recognizing the importance of the Professional role and related competencies, in the next iteration of the course, we made informed adjustments to lecture content (eg, added professionalism lecture and case discussions) and the assessment blueprint to address this finding.

This study has four main limitations. First, student performance on the final exam was examined holistically, and performance on individual questions was not considered. Failing the exam does not necessarily equate to being unable to demonstrate achievement of specific competencies as they may have gotten some competency-focused questions correct, and the opposite also holds true where passing the exam does not guarantee readiness in all competencies. ${ }^{23}$ Future work should map each question to relevant competencies and evaluate student performance for each question. Second, we did not consider student perspectives of whether the assessments provide ample opportunities to achieve EOs. There is value in considering both students' and instructors' perceptions of assessments, as they can differ, and our next steps should triangulate student feedback as well as their confidence related to practice readiness with that of faculty perspectives. ${ }^{8,10,24-}$ ${ }^{26}$ Third, although no student failed more than two assessments in this cohort, the possibility remains that this may be the case in future cohorts which is why continuous monitoring of student performance in each assessment, and careful blueprinting of assessments (adequately plan how assessments align and overlap with intended objectives) is required to ensure effective learning towards practice readiness. Finally, as we only considered one course, mapping all assessments across the program may provide further evidence of student practice readiness. 
Despite limitations, this study extends our current curriculum mapping work by adding an additional layer of assessment mapping to EOs. Our work emphasizes the importance of designing assessments that provide sufficient opportunities for students to demonstrate achievement of practice readiness before embarking on APPE rotations.

\section{CONCLUSION}

Assessments in our course align with updated AFPC EOs and there are enough assessments for students to demonstrate readiness in several of the roles. Assessment mapping is an essential step to ensure alignment of EOs and assessments in a competency-based education program. It is important to provide students with multiple opportunities to demonstrate achievement of learning outcomes to help ensure practice readiness for APPEs.

\section{ACKNOWLEDGMENTS}

This project was supported by the Teaching Innovation Grant and the Leslie Dan Faculty of Pharmacy at the University of Toronto. We would like to also acknowledge the Education Advisory Committee.

\section{REFERENCES}

1. Canadian Council for the Accreditation of Pharmacy Programs (CCAPP). Accreditation Standards for Canadian First Professional Degree in Pharmacy Programs. Published January 2018. https://ccapp.ca/wpcontent/uploads/2020/10/July7-CCAPP-Professional-Standards-ENG.pdf. Accessed July 22, 2021.

2. Association of Faculties of Pharmacy of Canada. AFPC Educational Outcomes for First Professional Degree Programs in Pharmacy in Canada 2017. Published June 2017. https://www.afpc.info/system/files/public/AFPCEducational\%20Outcomes\%202017_final\%20Jun2017.pdf. Accessed January 18, 2021.

3. National Association of Pharmacy Regulatory Authorities (NAPRA). Professional Competencies for Canadian Pharmacists at Entry to Practice. Published March 2014. https://napra.ca/sites/default/files/201708/Comp_for_Cdn_PHARMACISTS_at_EntrytoPractice_March2014_b.pdf. Accessed July 22, 2021.

4. Stupans I, et al. Nationwide collaborative development of learning outcomes and exemplar standards for Australian pharmacy programs. Int J Pharm Pract. 2015;23: 283-91. doi: 10.1111/ijpp.12163

5. General Pharmaceutical Council. Future Pharmacists Standards for the Initial Education and Training of Pharmacists; General Pharmaceutical Council: London, UK; 2011. Published May 2011. https://www.pharmacyregulation.org/sites/default/files/document/gphc_future_pharmacists_may_2011.pdf. Accessed July 22, 2021.

6. Medina MS, Plaza CM, Stowe CD, et al. Center for the Advancement of Pharmacy Education (CAPE) Educational Outcomes 2013. Am J Pharm Educ 2013;77(8): Article 162. doi: 10.5688/ajpe778162

7. Abdallah O, Ageeb RA, Elkhalifa WHI, et al. Evaluating prescribing competencies covered in a Canadianaccredited undergraduate pharmacy program in Qatar: a curriculum mapping process. BMC Med Educ. 2020;20(1):253. doi:10.1186/s12909-020-02109-1

8. Hardy YM, Marshall JL. "It's like rotations, but in the classroom": creation of an innovative course to prepare students for advanced pharmacy practice experiences. Curr Pharm Teach Learn. 2017(9):1129-1140. doi:10.1016/j.cptl.2017.07.009

9. Beatty SJ, Katherine KA, Ha J, Matsunami M. Measuring preadvanced practice experience outcomes as part of a PharmD capstone experience. Am J Pharm Educ. 2014;78(8):Article 152. doi: 10.5688/ajpe788152

10. Gilliam E, Nuffer W, Thompson M, Vande Griend J. Design and activity evaluation of an Advanced-Introductory Pharmacy Practice Experience (aIPPE) course for assessment of student APPE-readiness. Curr Pharm Teach Learn. 2017;9(4):595-604. doi: 10.5688/ajpe8358

11. Brown PC, Roediger (III) HL, McDaniel MA. Make It Stick. Harvard University Press; 2014.

12. Walvoord BE, Anderson VJ. Effective Grading: A Tool for Learning and Assessment in College. John Wiley \& Sons; 2011.

13. Richards J. A Guide to Curriculum Renewal at the University of Toronto. Accessed February 4, 2021. https://teaching.utoronto.ca/wp-content/uploads/2017/04/A-Guide-to-Curriculum-Renewal-at-the-University-ofToronto-2017.pdf

14. Hurtubise L, Roman B. Competency-Based Curricular Design to Encourage Significant Learning. Curr Probl Pediatr Adolesc Health Care. 2014;44(6):164-169. doi:10.1016/j.cppeds.2014.01.005

15. Norcini J, Anderson MB, Bollela V, et al. 2018 Consensus framework for good assessment. Med Teach.:9. 2018;40(11):1102-1109. doi: 10.1080/0142159x.2018.1500016 
16. Holmboe ES, Sherbino J, Long DM, Swing SR, Frank JR, International CBME Collaborators. The role of assessment in competency-based medical education. Med Teach. 2010;32(8):676-682. doi:10.3109/0142159X.2010.500704

17. Hodges B. Assessment in the post-psychometric era: Learning to love the subjective and collective. Med Teach. 2013;35(7):564-568. doi:10.3109/0142159X.2013.789134

18. Dennis VC, May DW, Kanmaz TJ, Reidt SL, Serres ML, Edwards HD. Pharmacy Student Learning During Advanced Pharmacy Practice Experiences in Relation to the CAPE 2013 Outcomes. Am J Pharm Educ. 2016;80(7):127. doi:10.5688/ajpe807127

19. Poulton A, Rose $\mathrm{H}$. The importance of health advocacy in Canadian postgraduate medical education: current attitudes and issues. Can Med Educ J. 2015;6(2):e54-e60. doi:10.36834/cmej.36665

20. Bandiera G, Sherbino J, Frank JR, eds. The CanMEDS Assessment Tool Handbook: An Introductory Guide to Assessment Methods for the CanMEDS Competencies. Royal College of Physicians and Surgeons of Canada; 2006.

21. Tucci M, Tong K, Chia K, DiVall M. Curricular and Co-curricular Coverage of Leadership Competencies and the Influence of Extracurricular Engagement on Leadership Development. Am J Pharm Educ. 2019;83(2):6535. doi:10.5688/ajpe6535

22. Janke KK, Nelson MH, Bzowyckyj AS, Fuentes DG, Rosenberg E, DiCenzo R. Deliberate Integration of Student Leadership Development in Doctor of Pharmacy Programs. Am J Pharm Educ. 2016;80(1):2. doi:10.5688/ajpe8012

23. Eva KW, Bordage G, Campbell C, et al. Towards a program of assessment for health professionals: from training into practice. Adv Health Sci Educ Theory Pract. 2016;21(4):897-913. doi: 10.1007/s10459-015-9653-6

24. Porter AL, Barnett SG, Gallimore CE. Development of a Holistic Assessment Plan to Evaluate a Four-Semester Laboratory Course Series. Am J Pharm Educ. 2017;81(2):33. doi:10.5688/ajpe81233

25. Gruenberg K, Hsia S, O’Brien B, O’Sullivan P. Exploring Pharmacy Students' Readiness for the Transition to Advanced Pharmacy Practice Experiences from Multiple Perspectives. Am J Pharm Educ. Published online February 11, 2021:8358. doi:10.5688/ajpe8358

26. Zibrowski EM, Singh SI, Goldszmidt MA, et al. The sum of the parts detracts from the intended whole: competencies and in- training assessments. Med Educ. 2009;43(8):741-748. doi: 10.1111/j.13652923.2009.03404.x 


\begin{tabular}{ll}
\hline ROLE & DEFINITION \\
\hline CARE PROVIDER & $\begin{array}{l}\text { As Care Providers, pharmacy graduates } \\
\text { provide patient-centred pharmacy care by using } \\
\text { their knowledge, skills and professional } \\
\text { judgement to facilitate management of a } \\
\text { patient's medication and overall health needs } \\
\text { across the care continuum. Care Provider is the } \\
\text { core of the discipline of pharmacy. } \\
\text { As Communicators, pharmacy graduates } \\
\text { communicate effectively in lay and professional } \\
\text { (CM) }\end{array}$ \\
$\begin{array}{l}\text { language, using a variety of strategies that take } \\
\text { into account the situation, intended outcomes of } \\
\text { the communication and diverse audiences. } \\
\text { As Collaborators, pharmacy graduates work } \\
\text { collaboratively with patients and intra- and } \\
\text { inter-professional teams to provide safe, } \\
\text { effective, efficient health care, thus fulfilling the } \\
\text { needs of the community and society at large. }\end{array}$
\end{tabular}

\section{LEADER- MANAGER (LM)}

\section{HEALTH ADVOCATE (HA)}

\section{SCHOLAR (SC)}

PROFESSIONAL (PR)
As Leaders and Managers, pharmacy graduates engage with others to optimize the safety, effectiveness and efficiency of health care and contribute to a vision of a high-quality health care system.

As Health Advocates, pharmacy graduates demonstrate care for individual patients, communities and populations by using pharmacy expertise to understand health needs and advance health and well-being of others.

As Scholars, pharmacy graduates take responsibility for excellence by applying medication therapy expertise, learning continuously, creating new knowledge and disseminating knowledge when teaching others.

As Professionals, pharmacy graduates take responsibility and accountability for delivering pharmacy care to patients, communities and society through ethical practice and the high standards of behaviour that are expected of selfregulated professionals. The Professional role is the overarching ethos of the discipline of pharmacy.
KEY COMPETENCIES* - Pharmacy Graduates are able to:

CP1: Practise within the pharmacist scope of practice and expertise.

CP2: Provide patient-centred care.

CP3: Actively contribute, as an individual and as a member of a team providing care, to the continuous improvement of health care quality and patient safety.

CM1: Communicate in a responsible and responsive manner that encourages trust and confidence.

CM2: Communicate in a manner that supports a team approach to health promotion and health care.

CL1: Work effectively with members of the health team including patients, pharmacy colleagues and individuals from other professions.

CL2: Hand over the care of a patient to other pharmacy team members and non-pharmacy team members to facilitate continuity of safe patient care. LM1: Contribute to optimizing health care delivery and pharmacy services.

LM2: Contribute to the stewardship of resources in health care systems.

LM3: Demonstrate leadership skills.

LM4: Demonstrate management skills.

HA1: Respond to an individual patient's health needs by advocating with the patient within and beyond the patient care environment.

HA2: Respond to the needs of communities or populations they serve by advocating with them for system-level change in a socially accountable manner. SC1: Apply medication therapy expertise to optimize pharmacy care, pharmacy services and health care delivery.

SC2: Integrate best available evidence into pharmacy practice.

SC3: Contribute to the creation of knowledge or practices in the field of pharmacy.

SC4: Teach other pharmacy team members, the public and other health care professionals including students.

PR1: Committed to apply best practices and adhere to high ethical standards in the delivery of pharmacy care.

PR2: Able to recognize and respond to societal expectations of regulated health care professionals. PR3: Committed to self-awareness in the management of personal and professional well being.

Reprinted with permission from the Association of Faculties of Pharmacy of Canada

"Within each key competency, there are enabling competencies that are relational sub-components of the key competency. While not shown, enabling competencies are available in the AFPC EO 2017 document. $^{2}$ 
Table 2. Overview of PHM330 Preparation for APPE Course Assessments

\begin{tabular}{|c|c|c|}
\hline Assessment & Weighting (\%) & Description/Objectives \\
\hline $\begin{array}{l}\text { Patient Case } \\
\text { Presentation (Video } \\
\text { Assignment) }\end{array}$ & 10 & $\begin{array}{l}\text { Students are given a case-based scenario and presentation } \\
\text { framework. For this assignment students are expected to } \\
\text { create a video simulating presenting the patient case to } \\
\text { their preceptor while on an APPE rotation. In the video, } \\
\text { they are asked to provide a brief description of the patient } \\
\text { (including background and demographics), the primary } \\
\text { reason for the patient encounter, the patient's reported } \\
\text { medical experience, comprehensive medical history, } \\
\text { identification of drug therapy problems, and the } \\
\text { prioritization of multiple drug therapy problems. }\end{array}$ \\
\hline $\begin{array}{l}\text { Documentation } \\
\text { Assignment }\end{array}$ & 15 & $\begin{array}{l}\text { Students are given a case-based scenario and a } \\
\text { documentation framework. Students are asked to prepare a } \\
\text { pharmacy note that demonstrates how they would } \\
\text { document the interaction outlined in the scenario which } \\
\text { involves the patient, their family member, and the } \\
\text { community pharmacist. }\end{array}$ \\
\hline $\begin{array}{l}\text { Critical Appraisal } \\
\text { (Two-part assignment } \\
\text { Individual and Group } \\
\text { component) }\end{array}$ & 10 & $\begin{array}{l}\text { Students are given a primary research article and critical } \\
\text { appraisal framework. Students are expected to critically } \\
\text { appraise the article related to osteoporosis treatment, and } \\
\text { reflect on inclusion/exclusion criteria, primary and } \\
\text { secondary outcomes, patient groups involved, bias, } \\
\text { generalizability of safety and efficacy data, clinical } \\
\text { benefits vs. side effects. }\end{array}$ \\
\hline $\begin{array}{l}\text { Community Practice } \\
\text { Written Assignment }\end{array}$ & 10 & $\begin{array}{l}\text { Students are provided with a case-based scenario and } \\
\text { prescription. Students are expected to review the case, } \\
\text { audit the prescription, and advocate for patient access to } \\
\text { the medication. }\end{array}$ \\
\hline Care Plan Assignment & 20 & $\begin{array}{l}\text { Students are given a case-based scenario. Students are } \\
\text { expected to identify and prioritize drug therapy problems, } \\
\text { evaluate goals of therapy, assess various interventions to } \\
\text { resolve drug therapy problems, justify recommendations } \\
\text { that take into consideration efficacy, safety, convenience, } \\
\text { and cost, and create a follow-up plan. }\end{array}$ \\
\hline Final Exam & 35 & $\begin{array}{l}\text { Students are given a comprehensive multiple choice final } \\
\text { exam. The exam blueprint includes key course content } \\
\text { areas: patient care process/presenting cases, medication } \\
\text { reconciliation, documentation, power searching, } \\
\text { interpreting lab values, community practice, } \\
\text { professionalism, family health teams, feedback, and } \\
\text { enablers of effective pharmacy practice. }\end{array}$ \\
\hline
\end{tabular}


Table 3. Assessment to AFPC Competency Map \& Student Failure Pattern

\begin{tabular}{|c|c|c|c|c|c|c|c|}
\hline \multirow[b]{2}{*}{ Role } & \multirow[b]{2}{*}{$\mathrm{KC}^{\mathbf{a}}\left(\mathbf{E C}^{\mathbf{b}}\right)$} & \multicolumn{6}{|l|}{ Assessment } \\
\hline & & $\begin{array}{l}\text { 1) Patient Case } \\
\text { Presentation } \\
(\mathrm{n}=)\end{array}$ & $\begin{array}{l}\text { 2) Documentation } \\
(\mathrm{n}=)\end{array}$ & $\begin{array}{l}\text { 3) Critical } \\
\text { Appraisal (n=) }\end{array}$ & $\begin{array}{l}\text { 4) Community } \\
\text { Practice }(n=)\end{array}$ & 5) Care Plan (n=) & $\begin{array}{l}\text { 6) Final Exam } \\
(\mathrm{n}=)\end{array}$ \\
\hline \multirow[t]{3}{*}{ Care Provider (CP) } & $\mathrm{CP} 1(\mathrm{n} / 5)$ & 4 & 5 & 1 & 2 & 4 & 5 \\
\hline & CP2 (n/5) & 2 & 5 & 0 & 3 & 5 & 5 \\
\hline & CP3 (n/2) & 1 & 1 & 0 & 0 & 2 & 2 \\
\hline \multirow{2}{*}{ Communicator $(\mathrm{CM})$} & CM1 (n/7) & 5 & 6 & 3 & 7 & 5 & 7 \\
\hline & $\mathrm{CM} 2(\mathrm{n} / 4)$ & 4 & 4 & 0 & 4 & 2 & 4 \\
\hline \multirow[t]{2}{*}{ Collaborator (CL) } & CL1 (n/3) & 3 & 3 & 3 & ( & 3 & 3 \\
\hline & CL2 (n/3) & 3 & 3 & 0 & 3 & 3 & 0 \\
\hline \multirow[t]{4}{*}{ Leader-Manager (LM) } & LM1 (n/4) & 0 & 0 & 0 & 0 & 0 & 0 \\
\hline & $\mathrm{LM} 2(\mathrm{n} / 3)$ & 0 & 0 & 0 & 1 & 0 & 0 \\
\hline & LM3 (n/1) & 0 & 0 & 0 & 0 & 0 & 0 \\
\hline & LM4 (n/2) & 0 & 0 & 0 & 0 & 0 & 0 \\
\hline \multirow[t]{2}{*}{ Health Advocate (HA) } & HA1 (n/3) & 0 & 0 & 0 & 1 & 2 & 0 \\
\hline & $\mathrm{HA} 2(\mathrm{n} / 2)$ & 0 & 0 & 0 & 0 & 0 & 0 \\
\hline \multirow[t]{4}{*}{ Scholar (SC) } & $\mathrm{SC} 1(\mathrm{n} / 3)$ & 0 & 3 & 3 & 1 & 3 & 0 \\
\hline & $\mathrm{SC} 2(\mathrm{n} / 4)$ & 0 & 3 & 3 & 0 & 4 & 4 \\
\hline & $\mathrm{SC} 3(\mathrm{n} / 2)$ & 0 & 0 & 2 & 0 & 0 & 0 \\
\hline & $\mathrm{SC} 4(\mathrm{n} / 4)$ & 0 & 1 & 1 & 0 & 0 & 0 \\
\hline \multirow[t]{3}{*}{ Professional (PR) } & PR1 (n/4) & 1 & 1 & 0 & 1 & 1 & 4 \\
\hline & PR2 (n/6) & 0 & 0 & 0 & 1 & 0 & 6 \\
\hline & PR3 (n/4) & 0 & 0 & 0 & 0 & 0 & 4 \\
\hline \multicolumn{8}{|l|}{ Student Performance ${ }^{\mathrm{c}}$} \\
\hline A & & $X$ & $X$ & $\square$ & $\square$ & $\square$ & $\square$ \\
\hline B & & $\mathrm{X}$ & $\square$ & $\mathrm{X}$ & $\square$ & $\square$ & $\square$ \\
\hline $\mathrm{C}$ & & $\square$ & $\mathrm{X}$ & 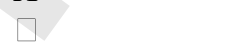 & $\square$ & $\square$ & $\mathrm{X}$ \\
\hline D & & $\mathrm{X}$ & $\mathrm{X}$ & $\square$ & $\square$ & $\square$ & $\square$ \\
\hline
\end{tabular}

